\title{
Drafting a composite indicator of validity for regulatory models and legal systems
}

\author{
Andrea Ciambra ${ }^{1}$, and Pompeu Casanovas ${ }^{1}$ \\ ${ }^{1}$ UAB Institute of Law and Technology, Universitat Autònoma de Barcelona, Barcelona, Spain \\ andrea.ciambralgmail.com \\ pompeu.casanovas@uab.cat
}

\begin{abstract}
The aim of this paper is to lay the groundwork for the creation of a composite indicator of the validity of regulatory systems. The composite nature of the indicator implies a) that its construction is embedded in the long-standing theoretical debate and framework of legal validity; b) that it formally contains other sub-indicators whose occurrence is essential to the determination of validity. The paper suggests, in other words, that validity is a second-degree property, i.e., one that occurs only once the justice, efficiency, effectiveness, and enforceability of the system have been checked.
\end{abstract}

Keywords. Validity $\cdot$ indicators $\cdot$ regulatory models $\cdot$ regulatory systems $\cdot$ Privacy Impact Assessment

\section{$1 \quad$ Introduction}

The aim of this preliminary and exploratory study is to lay the groundwork for the creation of a composite indicator of the legal validity of norms. The composite nature of the indicator implies $a$ ) that its construction is embedded in the long-standing theoretical debate and framework of legal validity; $b$ ) that it formally contains other sub-indicators whose occurrence is essential to the determination of validity. The study suggests, in other words, that validity is a secondary property of a legal norm, i.e., one that occurs only once the norm's justice $(J)$, efficiency $\left(E_{y}\right)$, effectiveness $\left(E_{s}\right)$, and enforceability $\left(E_{c}\right)$ have been proved. This basic hypothesis can be rewritten in a plainer fashion as:

$$
V_{n} \leq\left(J+E_{y}+E_{s}+E_{c}\right)
$$

where the norm's legal validity $V_{\mathrm{n}}$ is less than or equal to the sum of the four subindicators. This also suggests that the norm's compliance with all four sub-indicators is a necessary and sufficient condition for its legal validity, i.e., that the occurrence of all four sub-indicators implies the norm's validity in a regulatory system previously defined:

$$
\left(J+E_{y}+E_{s}+E_{c}\right) \Leftrightarrow V_{n}
$$

These are not to be understood as formulae, but as simple way to convey a first intuition about validity. There are two tasks to comply with. The first one is theoretical: 
we should set a sound conceptual framework. The second one is technical: once concepts are cleared up, we can proceed to construct the composite indicator.

The hypothesis does not assert the validity of all types of norms and normative systems, but only that in a regulatory model it becomes possible to assign the specific validity of the regulations, i.e., the validity of the system as a whole according to the previous occurrence of these sub-indicators. In this way, very likely, what the composite indicator really measures is the institutional strengthening of the whole system. That is to say, the emergent pragmatic aspect of regulatory systems that we can equate with their legal existence.

The analysis of the state of the art of the theoretical debate on legal validity highlights an unresolved issue ${ }^{1}$ in the determination of $a$ ) a generalisable threshold for the existence of a norm's validity and, $b$ ) the assessment of the concept of legal validity as a continuum or gradient rather than a discrete quality of a norm (i.e., a yes/no dichotomy). This paper starts briefly from the study of this debate (Section 2) to locate its working hypothesis into the theoretical framework of legal validity. It is carried out in tight connection with the objectives of CAPER, ${ }^{2}$ a large-scale collaborative project within the 7th Framework Programme of the European Union (EU) that aims to build an information-sharing Internet platform for the detection and prevention of organised crime.

It also analyses structural issues related to the construction of composite indicators (especially in the social sciences as well as in non-quantitative, discursive contexts) to advance a tentative indicator for the benchmarking or 'measurement' of the CAPER Regulatory Model (CRM), i.e. the specific set of rules laid down to run the government of the platform and its compliance with European and National regulations, including ethical principles, Data Protection Impact Assessments, and Best Practices mentioned in the new draft of the Regulation (Section 3). Section 4 identifies a number of research paths that, even besides the advances of the CAPER project, unfold thanks to the development of a technically-reliable indicator of validity for regulatory models.

\section{The Theoretical Debate: Legal Validity}

The definition of under what conditions law and norms can be considered valid is one of the most disputed debates in legal theory and the philosophy of law, a "major jurisprudential battleground" [6], the "pineal gland of law" [5], as well as a litmus test to identify the field's main theoretical fracture lines. The contrast between different schools of thought on legal validity lies essentially in the inevitable relation between and potential overlap of legality and morality, i.e., the middle ground between what law is and what it ought to be.

1 See Hage and von der Pfordten [1] and, in particular, Posher [2] and Spaak [3], as well as Grabowski [4]. For a general view and the general shape of the debate, see Pattaro [5].

2 CAPER is the acronym for «Collaborative information Acquisition, Processing, Exploitation, and Reporting for the prevention of organised crime». Curiously enough, a valuable work on indicator validation in the context of environmental social impact assessment by Bockstaller and Girardin, mentioned later in this paper, also refers to the development of another 'CAPER' project, namely, the «Concerted Action of Pesticide Environmental Risk indicators». The two projects should not, of course, be confused and all mentions in this paper refer to the former. 
Historically, the debate has polarised across a continuum that spans from natural lawyers' morality thresholds on one extreme (an unjust law is certainly not law) to positivist law's formalist tests on the other end (insofar as a norm abides by the formal requirements and conventions overtly accepted by a given political and social community, it is valid law). These two extremes diverge significantly also in epistemological terms.

Broadly speaking, natural law considers, on the one hand, law as a consequence or a subsequent derivation of the fundamental moral standards, principles, and values embedded in a community. This assumption allows natural lawyers to perform the validity assessment ex ante, i.e., as soon as the norm stems from the moral endowment of the community, it is inevitably just. On the other hand, positivist lawyers test validity once the norm is established, since they are concerned with the respect of the procedures and process that led to the ultimate formulation of the norm. The legal validity of a norm, therefore, "is established not by arguments concerning its value and justification but rather by showing that it conforms to tests of validity laid down by some other rules of the system" [7]. Positivists move the validity test more and more backwards up to a core of fundamental norms-i.e., "those ultimate rules of recognition" that are a "matter of social fact" [6] that cannot be contested lest the whole legal system be questioned. Positivists, in other words, hold an idea of law as "that which is" rather than "that which ought to be" [8]. This ex post approach exposes the positivist understanding of just or valid law to a historical vulnerability and a recurrent criticism, emphasising the attempt of positivist lawyers to justify as being valid (to the extent that they are formally correct) certain norms, laws, and policies that would generally raise moral concerns when cast against the background of (potentially) universal or majoritarian principles and values.

Despite the theoretical conundrums and the need to locate each current of thought at a given point on the 'validity debate' continuum, most readings of the validity problem imply a controversial issue of subjectivity and relativism and emphasise the lack of a defined, generalisable, adaptable and context-free measurement of legal validity, i.e., the lack of a reliable indicator that-whatever the legal context, juridical structure, and constitutional/institutional order - may signal a norm's legal validity or invalidity into the regulatory system. The theoretical debate on legal validity underscores, moreover, the importance of language, meaning, and semantic contextualisation in the attempt to abstract a general concept of validity. This emphasis has two main analytical implications.

First, any advance in this field needs to avoid the risk of trivialising the issue as of linguistic or cultural misunderstanding, i.e., the assumption that, since many scholars have analysed the validity issue from the semantic perspective of either certain languages ${ }^{3}$ or certain specific fields of application (e.g., the practice of law in court or the normative underpinnings of law- and policy-making), the different contributions to the debate may after all be agreeing on essential concepts and (more or less inadvertently) mystifying or baffling their mutual dialogue by means of ambiguous, relative or unsettled discursive vehicles and semantic structures.

Second - and consequently_, any advance in the validity debate should try to overcome these persistent definitional uncertainty and endemic 'relativism', strive for a notion of the validity concept which may reliably and flexibly used in diverse contexts and under

3 See, for instance, the detailed analysis of the validity debate in German philosophy of law carried out by Grabowski on Kelsen, Radbruch, Dreier, Alexy and Habermas [4]. 
varying conditions, and elicit the immediate and unequivocal understanding of the recipients and the users of norms - be they citizens, lawyers, lawmakers or scholars.

There are at least two ways of tackling this problem. From a logical point of view, validity can be faced as an emergent semantic property of inferential processes and then linked to the argumentative discourse on normative semantics. This is the way lately chosen, for instance, by Prakken and Sartor [9]: arguments about norms are modelled as the application of argument schemes to knowledge bases of facts and norms. But, from an empirical point of view, this normative approach does not help to know how the system works.

From an empirical approach, the problem can be described as a controlled induction process. The assumption is that validity is a second order property of a regulatory model that applies to the evaluation of regulatory systems. A regulatory system can be defined as a set of functionally interacting elements (not, or not only, as a set of logically consistent norms). A regulatory model tests how well the system is working-a process of assessing performance against some stated criteria or a known measure (i.e., a benchmark). This is why it makes sense to construct indicators to validate the system [10].

\section{The Construction of the Indicator}

This section of the paper lays the groundwork for further research on and assessment of a new composite indicator of validity for regulatory systems. We are not the first to suggest composite indicators for the legal field. Vallbé and Casellas [28] are proposing a model for the costs of discovery of legal information, the relationship between governmental online presence and legal publication, and the quality of regulation. Vallbé [29] just constructed a composite indicator for judicial performance (a judicial regional authority index, related to the degree of decentralization of states).

But very likely ours is one of the first attempts to model in this way some concepts stemming from legal theory. It should be noted too that this paper does not start from a normative point of view. Regulatory spaces [11] or meta-regulatory strategies [12] have been already proposed from a socio-legal perspective to cope with the transnational plurality of normative sources. It is our contention that we can take a different and simpler starting point. The process of construction and validation of the indicator suggested here draws from several examples and methodological notes in current literature and focuses in particular on a field that has been developed significantly over the last two decades and may serve, by all means, as a lesson learned or good practice in this regard: privacy impact assessments (PIAs). .

\subsection{Preliminary Lessons: the Case of Privacy Impact Assessments}

Impact Assessments (IA) consist of all sorts of studies, measurements and reflections about the social, ethical and legal effects and consequences of certain policies, regulations and practices. From the past twenty years on it has become commonplace to apply IA to privacy (Privacy Impact Assessments, PIAs), regulations (RIAs), surveillance (SIAs) and data protection (DPIAs). Implementing a PIA or a DPIA means a sort of monitoring audit that goes along the process of creating, testing, reviewing and eventually enforcing a regulatory tool (including technological projects and economic 
planning). They have been adopted mainly to evaluate intended legislation and public policies in PIAs have been currently adopted by Common Law countries like USA, Canada, UK, Australia, and New Zealand for the protection of civil (human) rights regarding personal data [13]. A PIA is conceived as a methodology and a process for identifying and evaluating risks to privacy, checking for compliance with legislation and aiming at avoiding or mitigating those risks [14].

PIAs are the immediate precedent for Data Protection Impact Assessments (DPIAs), as foreseen by the EU Directive proposal. The IA Document defines DPIAs as a PIA: "A process whereby a conscious and systematic effort is made to assess privacy risks to individuals in the collection, use and disclosure of their personal data. DPIAs help identify privacy risks, foresee problems and bring forward solutions". Constructing an empirical notion of validity is key to evaluate the functioning of regulatory systems after a PIA (or DPIA) has been carried out. ${ }^{4}$

\subsection{A Composite Indicator of Legal Validity}

Composite indicators are increasingly valued in the social sciences because of their "ability to integrate large amounts of information into easily understood formats for a general audience" [15]. A composite indicator is a synthetic index of several individual indicators, a quality that allows analysts to present complex content more rapidly, compare different contexts or timeframes more intuitively, and reduce the amount of data or graphic content that needs to be used to deliver the necessary information. Their convenience and growing systematic use in a number of policy fields and academic sectors demand, however, a degree of methodological consciousness that may add up to the indicator's credibility and reliability. Rather than one able to convey as much information as possible with the most compact index available, this study suggests the creation of an indicator whose composite nature is mostly qualitative by the moment. At least at its present stage.

Legal validity as a composite indicator implies that the object of the assessment is not (legally) valid unless all four sub-indicators reach a certain threshold. This indicator, in other words, to be applied as an evaluative tool, is not meant to compile synthetic information from a dataset; rather, it depends on its sub-indicators to show a certain value for it to be an actual measure of validity. The creation of the indicator is still at an embryonic stage of development. We tend to adhere to the general definitions and guidelines issued by the Organisation for Economic Cooperation and Development (OECD) about the construction of composite indicators. Even though the OECD has consistently increased its reliance on (and, proportionally, its careful methodological improvement of) composite indicators of economic and sustainability performance, especially in cross-country comparisons, its

4 According to the EU Commission Staff Working Paper SEC(2012) 72 final, a Data Protection Impact Assessment (DPIA) is a process whereby a conscious and systematic effort is made to assess privacy risks to individuals in the collection, use and disclosure of their personal data. DPIAs help identify privacy risks, foresee problems and bring forward solutions. The definition of these general concepts stems from D7.1, EU Commission Staff Working Paper SEC(2012) 72 final, the Joint Proposal for a Draft of International Standards on the Protection of Privacy with regard to the processing of Personal Data (Madrid, 2009), and Directives 95/46/EC, 2002/58/EC, and 2009/136/EC. 
guidance for the process of creating one are extremely useful even outside the scope of economics. The OECD's recommended 'checklist' [16] suggests a few fundamental steps towards the creation of a valid composite indicator: 1) defining a consistent theoretical framework for the selection of relevant variables, objectives, and potential recipients of the tool; 2) selecting adequate data according to "analytical soundness, measurability, ... and relevance of the indicators to the phenomenon being measured and the relationship to each other" [16]; and 3) normalisation of all indicators by weighing them to a ground coefficient, in order to make all variables comparable and the composite result homogeneous. At the current stage of work, the composite indicator of legal validity is at phase 2: the theoretical framework is already well enshrined in the long-standing debate on validity, normativity, legality, and morality; the following sub-sections start defining the sub-indicators by attaching them to a given variable and suggesting a suitable set of existing data to assess its occurrence and/or intensity. Fig. 1 shows the general structure of the model that we are fleshing out.

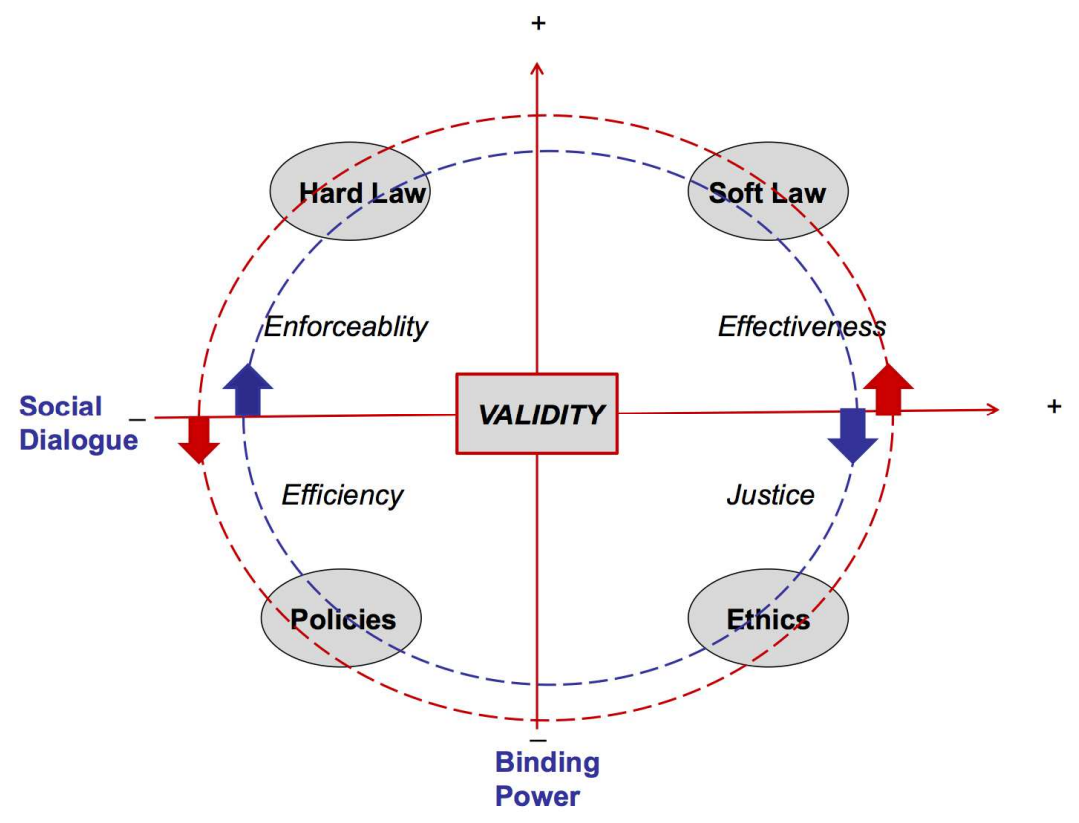

Fig. 1. Structure of the CAPER Regulatory Model. Source: [26, 27]

Sub-indicator No. 1: Efficiency. Efficiency is an indicator of governance that refers to the quality of the outcome produced (regulations, services or products): in this case, the relationship between regulatory systems and Agencies and Administration policies. In order to build this indicator for the EU Freedom, Security and Justice area, we are focusing only on one small part of the Rule of Law World Bank indicators, i.e., how well the regulatory system is able to perform within a multilevel governance 
organisation. Therefore, it refers primarily to its institutional strengthening (IS) dimension. (Do note that validity refers to IS as a second order property). IS points to the collective property that emerges from the process of implementing a model seeking a certain balance between the binding power of the rule of law and the dialogue among all the stakeholders, including the different polices, web service providers, and citizens. Two more related dimensions are at stake: the interoperability between databases and technological languages [17], and the multi-level inter- and intraorganisational dynamics.

Sub-indicator No. 2: Effectiveness. Effectiveness is an indicator of governance that refers to the relationship between the results achieved and the resources used (cost in relation to the outcomes achieved). We propose to measure the effectiveness of soft law mechanisms regarding non-binding regulations, directives and guidelines of the $\mathrm{UN}$ and the EU Commission. The performance of statements, principles, codes of conduct, and codes of practice can be summarised for Security Information Governance and Data Protection combining the COBIT maturity model and ISO 17799-as suggested by von Solms [18]. COBIT can be seen as being used on a strategic level, indicating the 'what' as far as governance is concerned. On the other hand, ISO 17799 can be seen more as being used on a lower level, specifying the 'how', as far as information security management is concerned [19].

Sub-indicator No. 3: Enforceability. Enforceability entails the possibility to be argued in court to ground a judicial ruling. It belongs to the adjudication legal system, in which certainty of law matters. In terms of measurement, enforceability presents a meaningful semantic challenge, since historically analysts and organisations have indulged in elaborate indicators of enforcement rather than enforceability, i.e., ex post analyses of the actual degree of compliance with an established norm rather than an analysis of a norm's potential for compulsoriness. A valuable example comes from studies on the rule of law and the performance of law enforcement and justice, especially on a global scale, at which comparable and normalised results are most needed [20]. Indicators such as the administrative processes that lead to a norm's enforcement, measurements of political influence or intervention in the enforcement process, and the respect of due process guarantees throughout all procedures are common indices of enforcement and compliance in this kind of studies.

The composite indicator suggested in this paper, however, looks more at a characterisation of enforceability at an earlier stage of the policy- and law-making processes, i.e., we are more interested in the possibility for practitioners and administrators to evaluate preliminarily whether a norm presents any issues when it comes to actual enforcement and prospective compliance by the act's recipients. Under common circumstances, of course, compliance is highly correlated to the hierarchical value of the legal vehicle used to implement it: in other words, it can be expected that a norm or act be more easily enforced if it is carried out through hard law or strictly mandatory provisions. A gap between a norm's legal vehicle-e.g., hard law in the form of a regulation - and the norm's capability to be implemented and enforced-e.g., bottlenecks in the administrative procedure, misled targeting, excessive costs-undermines 
the norm's validity, as it increases uncertainty and lowers effectiveness. Standard compliance metrics are generally drawn from corporate performance 5 or administrative auditing [21]. This paper aims to promote further academic debate on a middleground indicator of enforceability that would measure the potential for a smooth implementation process and the lack of any ethics- and performance-related shortcomings in the enforcement of a certain law or policy act.

Sub-indicator No. 4: Justice. The ethical criterion of justice, needed to deem whether a norm or law is valid or invalid, is perhaps the most controversial or questionable point in the methodological argument that designs the composite legal validity indicator suggested in this paper. The assessment of this indicator tends inevitably to a subjective appraisal of qualitative, non-tangible, and/or discursive data such as perception, opinions or 'feelings' about a subject's experience of justice in its relationship with society or authority. A more technical and quantitative analytical vantage point has focused, conversely, on justice as it is usually 'materialised' in court and procedure: part of this literature has developed, accordingly, a number of indicators to measure the performance of justice systems, especially in terms of effectiveness and social cost. ${ }^{6}$ Measurement and 'quantification' is therefore the most challenging issue raised by an 'ethical' indicator of justice.

The lack of data-especially when "a certain behaviour cannot be measured or no one has attempted to measure it" [15] —affects the reliability of the indicator. This is all the more true when dealing with a variable, the perception of justice, which can be parameterised only through discursive and content-related analysis of language 'vehicles', i.e., all those linguistic and semantic units that constitute communication, meaning, and ideas and whose cataloguing and typology may render a conceptual map of what is conceived as just in a growingly objective and socially-accepted way. The construction of such methodology_calling for an attempt to perfect certain techniques that are commonly adopted in discourse and content analysis in the social sciences and normalise an indicator of justice against a comparable and replicable minimum standard-presents perhaps the richest opportunity for further debate and research development. Metrics, typologies, data mining, bibliometrics, and content analysis all contribute to the potential toolkit that may provide the first-hand raw data needed to develop and validate the justice indicator envisioned and suggested in this paper.

5 Corporate services-e.g., the Compliance Week (http://www.complianceweek.com/)— information service are nowadays a full-fledged industry providing additional assistance and expertise to corporations interested in ethics and compliance audits.

6 Harvard University is developing a tailored project on indicators of safety, justice, and the rule of law, involving a number of academic and civil society institutions in six partner countries:

http://www.hks.harvard.edu/programs/criminaljustice/research-publications/measuring-theperformance-of-criminal-justice-systems/indicators-in-development-safety-and-justice. 


\subsection{Methodological Caveats on the Indicator's Validation}

The applications of a consistent and reliable indicator of legal validity are manifold. The possibility to assess - regardless of context and time- - whether a suggested regulation, norm or law passes a test of legal validity is necessary guidance for policy- and lawmakers. The composite nature of this indicator, moreover, implies that, insofar as the norm passes the validity test, it is also just, enforceable, effective in reaching its goals, and efficient in terms of resources or time needed. The indicator proposed in this paper, in other words, complies with the basic function of any indicator, i.e., "to reduce the volume and complexity of information which is required by decision makers" [22]. Such an indicator provides the analyst or the lawyer with a threshold after which validity is identified straightforwardly and relays, at the same time, "a complex message in a simplified manner" [23]. A composite indicator on validity, ideally, would condense convolute information on a norm's qualities in just one single measurement.

There are a number of methodological caveats that need to be taken into consideration when validating an indicator, especially if its design derives-as it is the case with legal validity-from the need to fill a theoretical vacuum with significant concrete implications in the routine activities of practitioners and professionals. We concur that the scientific and practical value of an indicator is intrinsically connected to its compliance with fundamental criteria of acceptability. Within the closed epistemic community of scholars, students, and practitioners of a given discipline, general consensus and acceptance validate an indicator "if it is scientifically designed, if the information it supplies is relevant, if it is useful and used by the end users" [24]. An indicator's design must respect generally-accepted rules and prescriptions; the feedback of relevant scientific peers must confirm the viability of the indicator as an analytical instrument; and the output of the indicator must be intelligible, accessible, and useful to the target recipients of the tool. This tri-partite scheme is commonly adopted in the literature about social composite indicators (see Fig. 2), especially in welldeveloped fields such as environmental impact assessment or sustainability studies. The design-feedback-output model can also be interpreted hierarchically, as with the "3S methodology" and the three progressive stages of "sui validatio", "scienciatis validatio", and "societatis validatio": this scholarship argues that the indicator's "credibility" grows proportionally to its ability to pass this cumulative test [25]. 


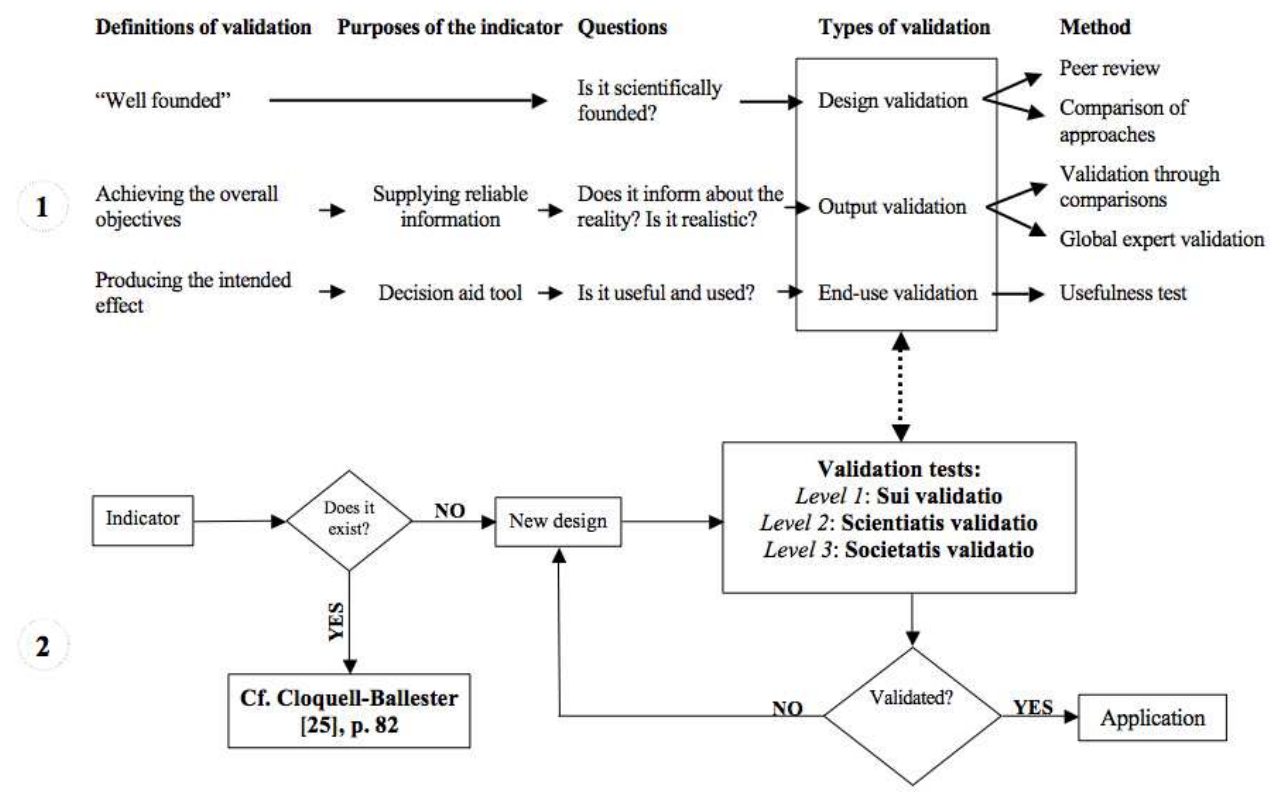

Fig. 2. Re-elaboration of the process flows of indicator validation in (1) Bockstaller and Girardin, [24], and (2) Cloquell-Ballester et al., [25]. The dashed line emphasises the convergence of both models on a tri-partite validation test.

Both tri-partite models of validation presented above are useful to effectively increase the scientific reliability of a new indicator and respond to the requirements of acceptability established as standard in a given community. This position paper, therefore, after outlining the main characteristics of its proposed indicator of legal validity, also recommends that this design and prospective analytical tool be subject to the scrutiny of peer researchers and practitioners in order to gather valuable feedback and responses as regards: $a$ ) the scientific adequacy of the model proposed in this paper; $b$ ) positive comparison between this indicator and analogous or comparable tools already validated by its recipients; and $c$ ) positive reception from potential end-users as far as the necessity, the appropriateness, and the practical potential of this indicator in its day-to-day, professional or 'routine' uses are concerned. Besides suggesting a new research agenda on this topic for the close future and invite all interested contributors to engage in the debate outlined above, this paper calls explicitly upon the users that this indicator has been tailored to: practitioners and professionals whose choices depend-to a varying degree-on the recognition of the validity of a certain norm, law or regulation. This empirical quandary and concrete objective have been the lynchpin and the true raison d'être of this work in the first place, and it is this specific group of recipients and potential users that the whole CAPER project and its deliverables are aimed at. 


\section{Prospective Practical Applications: the CAPER Project}

The CAPER project aims to create a common platform for the prevention of organised crime through sharing, exploitation and analysis of both open and private information sources. ${ }^{7}$ One of the main objectives of the project is to establish a common platform through which law enforcement agencies (LEAs) from different countries can share information to pool resources and improve mutual interoperability in their fight against organised crime. The development of the project envisages the analysis and collection of data not only from openly available sources such as televised, radio, and visual broadcasts or Internet content, but also from internal resources and information exclusively available to LEAs in the exercise of their functions. The sensitive content of the data and materials made available by LEAs to design and create the platform makes it all the more important for all actors involved in the project to test all proposed action and objectives against an indicator of validity, in order to clarify since the earliest stage of development that all planned measures meet a generallyaccepted standard of legitimacy.

The creation and validation of a reliable and context-free indicator of legal validity is, therefore, crucial for the development of the CAPER platform and the usability of its instruments. CAPER is also a valuable measurement of the complexity of cooperation, information sharing, and interoperability in such a sensitive field, in which LEAs manage significant amounts of delicate information and implement a number of actions that affect - one way or the other-different societal groups as well as the populace at large. There is an ethical red line lingering over the blurred boundary between the information that LEAs need to perform their duties and the information whose management requires additional regulation and caution as it enters the sphere of privacy of citizens and other subjects of law. The model of legal validity indicator suggested in this paper addresses this issue by 'quadrupling' the dimensions implied by the validity of a norm, measure or decision. An action set out by LEAs in the framework of the CAPER project, therefore, will be asked to pass a validity test that, per se, also confirms that this measure is efficient in terms of its practical implementation, effective in meeting strategic objectives and carrying out the necessary tasks, enforceable through the deployment of the available instruments and resources, and, most importantly, that this measure is just to the extent that it complies with privacy requirements and is not detrimental to the recipients' individual rights only for the sake of its application. For this set of reasons privacy impact assessments have been a relevant source of practices, examples, and information for the definition of this composite indicator. The CAPER project is a valuable starting point for the refinement of this kind of 'ethical' indicators and assessment protocols, even though issues of subjectivity, qualitative appraisal, and discursive/non-neutral techniques remain open to further public scrutiny and debate in the scientific community.

7 http://www.fp7-caper.eu/fr.html. 


\section{$5 \quad$ Conclusions and Future Work}

In this paper we have drawn the main lines to build up a regulatory model for the monitoring and evaluation of regulatory systems. We have suggested that validity is not a first-order property of the system, but a second-order property $a$ ) along the axis compulsoriness/social dialogue; $b$ ) the linear function four-tuple [enforceability, effectiveness, efficacy, justice]; and $c$ ) the resulting institutional strengthening. The Caper Regulatory Model (CRM) provides the benchmark with which this model will be tested to evaluate the functioning of the European platform for police interoperability to fight organised crime.

\section{References}

1. Hage, J.C., Pfordten, D. von der: Concepts in Law. Springer (2009)

2. Poscher, R.: The Hand of Midas: When Concepts Turn Legal, or Deflating the Hart-Dworkin Debate. In: Hage, P.J.C. and Pfordten, P.D. von der (eds.) Concepts in Law. pp. 99-115. Springer Netherlands (2009)

3. Spaak, T.: Explicating the Concept of Legal Competence. In: Hage, P.J.C. and Pfordten, P.D. von der (eds.) Concepts in Law. pp. 67-80. Springer Netherlands (2009)

4. Grabowski, A.: Juristic Concept of the Validity of Statutory Law. A Critique of Contemporary Legal Nonpositivism. Springer (2013)

5. Pattaro, E. ed: A Treatise of Legal Philosophy and General Jurisprudence Volume 1: The Law and The Right. Springer (2012)

6. Sartor, G.: Legal Validity as Doxastic Obligation: From Definition to Normativity. Law Philos. 19, 585-625 (2000)

7. Raz, J.: The authority of law: essays on law and morality. Oxford University Press, Oxford; New York (2009)

8. Gray, J.C.: The Nature and Sources of the Law. The Columbia University Press (1909)

9. Prakken, H., Sartor, G.: H. Prakken, G. Sartor, Formalising arguments about norms. In: K.D. Ashley (ed.), Legal Knowledge and Information Systems. JURIX 2013: The Twenty-sixth Annual Conference. IOS Press, Amsterdam, pp. 121-130 (2013)

10. Kaufmann, D., Kraay, A., Mastruzzi, M.: The Worldwide Governance Indicators: Methodology and Analytical Issues. Social Science Research Network, Rochester, NY (2010)

11. Lange, B.: Regulatory Spaces and Interactions: An Introduction. Soc. Leg. Stud. 12, 411-423 (2003)

12. Bomhoff, J., Meuwese, A.: The Meta-regulation of Transnational Private Regulation. J. Law Soc. 38, 138-162 (2011)

13. Wright, D., Wadhwa, K., de Hert, P., Kloza, D.: A Privacy Impact Assessment Frameworks for Data Protection and Privacy Rights. DJLS/2009 -2010/DAP/AG (2011) http://www.piafproject.eu/ref/PIAF_D1_21_Sept_2011.pdf 
14. Wright, D., de Hert, P.: Introduction to Privacy Impact Assessment. In: Wright, D. and de Hert, P. (eds.) Privacy Impact Assessment, LGTS, Springer, Berlin, Dordrecht, pp. 3-32 (2012)

15. Freudenberg, M.: Composite Indicators of Country Performance. Organisation for Economic Co-operation and Development, Paris (2003)

16. Handbook on constructing composite indicators: methodology and user guide. OECD, Paris (2008)

17. Wallwork, A., Baptista, J.: Understanding interoperability. In: Backhouse, J. (ed.) D4.1: Structured account of approaches on interoperability. pp. 19-28. FIDIS - Future of IDentity in the Information Society (2005)

18. Von Solms, B.: Information Security governance: COBIT or ISO 17799 or both? Comput. Secur. 24, 99-104 (2005)

19. Pretorius, E., Solms, P.B. von: Information Security Governance using ISO 17799 and COBIT. In: Jajodia, S. and Strous, L. (eds.) Integrity and Internal Control in Information Systems VI. pp. 107-113. Springer US (2004)

20. Agrast, M., Botero, J., Martínez, J., Ponce, A., Pratt, C.: The World Justice Project Rule of Law Index. The World Justice Project, Washington, DC (2012).

21. Measuring compliance effectiveness - our methodology. Australian Taxation Office, Camberra (2012)

22. Donnelly, A., Jones, M., O’Mahony, T., Byrne, G.: Selecting environmental indicator for use in strategic environmental assessment. Environ. Impact Assess. Rev. 27, 161-175 (2007)

23. Fisher, W.S.: Development and Validation of Ecological Indicators: an ORD Approach. Environ. Monit. Assess. 51, 23-28 (1998)

24. Bockstaller, C., Girardin, P.: How to validate environmental indicators. Agric. Syst. 76, 639-653 (2003)

25. Cloquell-Ballester, V.-A., Cloquell-Ballester, V.-A., Monterde-Díaz, R., Santamarina-Siurana, M.-C.: Indicators validation for the improvement of environmental and social impact quantitative assessment. Environ. Impact Assess. Rev. 26, 79-105 (2006)

26. Casanovas, P.: A Note on Validity in Law and Regulatory Systems (Position Paper). Quaderns de filosofia i ciència, 42, pp. 29-40 (2012)

27. Casanovas, P., Zeleznikow, J.: Online Dispute Resolution and Models of Relational Law and Justice. Presented at the Joint Workshop AICOL-SINTELNET at JURIX, 26th International Conference on Legal Knowledge and Information Systems , Bologna, Italy December 11 (2013)

28. Vallbé, J.J., Casellas, N.: What's the cost of e-Access to Legal Information? A composite indicator. Accessible on-line: http://goo.gl/yNn0xz. (2014)

29. Vallbé, J.J.: Measuring the Judicial Power of Regions: A Judicial Regional Authority Index. European Consortium for Political Research. Online: http://www.ecpr.eu/Events/PaperDetails.aspx?PaperID=16452\&EventID=12 (2014) 